\title{
Future initiatives to improve the health and wellbeing of Aboriginal and Torres Strait Islander peoples
}

\author{
Continuing to close the health gap will require innovation; long-term, systematic approaches that \\ improve the quality and integrity of data; collaborations and partnerships that reflect an ecological \\ approach to health, and recognition of the proper place and contribution of Aboriginal and Torres \\ Strait Islander peoples in Australian society
}

$\mathrm{t}$ long last there are signs that the gaps between the health of Aboriginal and Torres Strait Islander people and non-Indigenous people are closing but systematic, long-term action needs to continue both within and outside the health system to realise true health equality, and for us to know that we have achieved it.

According to the 2012 report of the Aboriginal and Torres Strait Islander Health Performance Framework, a number of positive trends in Aboriginal and Torres Strait Islander health include:

- the mortality rate has declined significantly (by $33 \%$ ) between 1991 and 2010 among people living in Western Australia, South Australia and the Northern Territory combined;

- deaths due to avoidable causes decreased significantly in WA, SA and the NT combined, down 24\% between 1997 and 2010;

- deaths from respiratory disease decreased significantly from 1997 to 2010, and the gap with non-Indigenous Australians has also narrowed; and

- mortality among infants aged less than 1 year declined by $62 \%$ between 1991 and 2010, perhaps reflecting the benefits of immunisation, improved access to primary health care services, the use of antibiotics and earlier evacuation to hospital for acute infections. ${ }^{1}$

Of course there remain areas where the gap persists or in some cases has grown, including chronic disease, injury, cancer, disability and low birthweight babies. It appears that in some areas (such as cancer) improvements in the quality, accessibility and impact of treatment are resulting in significantly improved death rates for non-Indigenous Australians, but Aboriginal and Torres Strait Islander people are missing out. The causes of this discrepancy seem to lie in disparities in stage at diagnosis, treatment received and survival rates.

Cutting across these trends are persistent gaps in the quality of data. Our inability to know whether large investments made in recent years in Aboriginal and Torres Strait Islander health are paying off should be a major focus for future strategies. In general, our population does not seem to be benefiting from the same level of sophisticated population-level tracking, health assessment or data integrity that majority populations take for granted. ${ }^{2}$ Good data are crucial, not just to know the

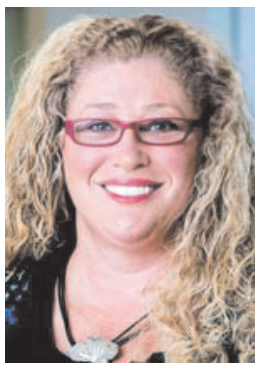

Kerry Arabena Director and Chair of and Chair $^{2}$

1Onemda VicHealth Koori Health Unit, University of Melbourne, Melbourne, VIC.

2 National Aboriginal and Torres Strait Islander Health Equality Council,
Canberra, ACT.

kerry.arabena@ unimelb.edu.au

doi: $10.5694 / \mathrm{mjal} 3.10816$

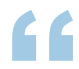

we will need to redress some of the less palatable aspects of the health system Indigenous Health, impact of what we have done, but to guide what we are doing.

In this context it is pleasing to see the recent process of developing a new national plan to guide future investments in Aboriginal and Torres Strait Islander health, developed through a collaborative process including Aboriginal and Torres Strait Islander peak bodies, communities, services, researchers, advocates and clinicians. ${ }^{3}$ The new national plan needs to set directions for the next 10 years and expand and align with an ecological view of health, include concepts important to Aboriginal and Torres Strait Islander peoples and influence other sectors that affect health, such as education, employment, housing and early childhood development. This multifocal approach could have implications for the design, implementation and evaluation of projects, and will necessitate a reconceptualisation of partnerships and collaborations, while fostering innovations and knowledge exchange.

Finally, we will need to redress some of the less palatable aspects of the health system that contribute to inequality, such as racism. ${ }^{4}$ Embodied in dubious practices, disparities in access and subtle variations in effort within health and other institutions and programs, racism has had and continues to have a real and damaging impact on the health of Aboriginal and Torres Strait Islander people. It is clear that full health equality cannot be achieved until racism and other practices that deny our status and rights as the original and First Peoples of Australia can be overcome. My hope is that not only do we redress racism in health and other systems, but that this nation recognises and enables each and every Aboriginal and Torres Strait Islander person the opportunity to rise to the full potential of our existence.

\section{Competing interests: No relevant disclosures.}

Provenance: Commissioned; not externally peer reviewed.

1 Australian Health Ministers' Advisory Council. Aboriginal and Torres Strait Islander health performance framework 2012 report. AHMAC: Canberra, 2012. http://www.health.gov.au/indigenous-hpf (accessed Jun 2013).

2 Australian Institute of Health and Welfare. Towards better Indigenous health data. Canberra: AlHW, 2013. (AlHW Cat. No. IHW 93.) http://www.aihw. gov.au/publication-detail/?id=60129543454 (accessed Jun 2013).

3 Department of Health and Ageing. National Aboriginal and Torres Strait Islander health plan. http://www.health.gov.au/natsihp (accessed Jun 2013).

4 Durey A, Thompson SC, Wood M. Time to bring down the twin towers in poor Aboriginal hospital care: addressing institutional racism and misunderstandings in communication. Intern Med J 2012; 42: 17-22. 